\title{
Magnetostriction of heavily deformed Fe-Co binary alloys prepared by forging and cold rolling
}

\author{
Shin-ichi Yamaura ${ }^{\dagger 1}$, Takashi Nakajima ${ }^{1}$, Takenobu Satoh ${ }^{2}$ Takashi Ebata $^{2}$ and Yasubumi Furuya ${ }^{3}$
}

1 Institute for Materials Research, Tohoku University, 2-1-1 Katahira, Aoba, Sendai 980-8577, Japan.

2 Tohoku Steel, Co., Ltd., 23 Nishigaoka, Murata, Murata-machi, Shibata 989-1393, Japan.

3 North Japan Research Institute for Sustainable Energy, Hirosaki University, 2-1-3 Matsubara, Aomori 030-0813, Japan.

$\dagger$ All correspondence should be addressed to yamaura@imr.tohoku.ac.jp

Keywords: iron-cobalt alloy, magnetostriction, magnetization, cold rolling, forging

\begin{abstract}
-
Magnetostriction of $\mathrm{Fe}_{1-\mathrm{x}} \mathrm{Co}_{\mathrm{x}}(\mathrm{x}=50-90$ at $\%)$ alloys prepared by forging and subsequent cold-rolling was studied as functions of alloy compositions and thermomechanical treatments. Magnetostriction of the as-forged $\mathrm{Fe}_{25} \mathrm{Co}_{75}$ alloy was 108 ppm and that of the as-cold rolled $\mathrm{Fe}_{25} \mathrm{Co}_{75}$ alloy measured parallel to the rolling direction (RD) was 128 ppm. The cold-rolled $\mathrm{Fe}_{25} \mathrm{Co}_{75}$ alloy possessed a nearly $\{100\}<011>$ texture, leading to the maximum magnetostriction of $140 \mathrm{ppm}$ when measured at an angle of $45^{\circ}$ to RD. Moreover, the fully annealed $\mathrm{Fe}_{25} \mathrm{Co}_{75}$ and $\mathrm{Fe}_{20} \mathrm{Co}_{80}$ alloys were gradually cold rolled and magnetostriction were measured. Results showed that the magnetostriction of those cold-rolled alloys drastically increased with increasing reduction rate. According to the XRD and TEM observations, intensity of the fcc peak gradually decreased with increasing reduction rate and that the alloys became to be in a bcc single state at a reduction rate higher than $90 \%$, leading to a drastic increase in magnetostriction.
\end{abstract}




\section{Introduction}

Magnetostriction is one of the functional properties of ferromagnetic materials, causing their shape/dimensions to change in an applied magnetic field. The use of magnetostrictive materials for actuators, sensors, oscillators and motors has been anticipated. In particular, as thin film of magnetostrictive alloys shows good compatibility with semiconductor manufacturing processes in the field of MEMS devices, much effort has been devoted to development of micro-sized high-sensitive magnetic sensors and energy harvesters by using magnetostrictive materials [1-5]. It is well-known that most ferromagnetic materials show a certain magnitude of magnetostriction. For example, pure iron possesses negative magnetostriction of about $-9 \mathrm{ppm}$ and cobalt shows relatively large negative magnetostriction of about $-52 \mathrm{ppm}[6]$, the largest among the pure metals.

There are some well-developed magnetostrictive materials [7-9]. Terfenol-D (Tb-Dy-Fe) is known to show giant magnetostriction larger than $2000 \mathrm{ppm}[10-12]$ and $\mathrm{TbCo}_{2}-\mathrm{DyCo}_{2}$ composite shows magnetostriction of about $800 \mathrm{ppm}$ [13]. Giant magnetostriction of Terfenol-D has been attributable to the magnetic domain rotation which causes internal strain [11]. Terfenol-D is commercially available, but as a single crystal in most cases, and is thus expensive. As for the origin of large magnetostriction of the $\mathrm{TbCo}_{2}-\mathrm{DyCo}_{2}$ composite, Yang et al. suggested that large magnetostriction of this material was attributable to the abnormal behavior of the magnetic and structural phase transition at the phase boundary between the $\mathrm{TbCo}_{2}$ and the $\mathrm{DyCo}_{2}$ phases and that this behavior was similar to the magnification behavior of piezoelectricity at the morphotropic phase boundary observed in the ferroelectric $\mathrm{PbZrO}_{3}-\mathrm{PbTiO}_{3}$ system (PZT) [13]. Some other giant magnetostrictive materials have also been reported [14]. Furthermore, Fe-Ga alloy possesses a magnitude of magnetostriction of about $400 \mathrm{ppm}$ and is known as Galfenol [15-20]. As clearly seen in the phase diagram of the Fe-Ga binary alloy system, the alloy has a phase boundary between the $\mathrm{D}_{3}$ ordered phase (bcc) and the $\mathrm{A} 2$ disordered phase (bcc $\alpha-\mathrm{Fe}$ ) at around the composition range of 15-25 at\%Ga. Fe-Ga alloy shows the largest magnetostriction in this composition range. Thus, it is conceivable that the large magnetostriction of $\mathrm{Fe}-\mathrm{Ga}$ alloy is due to enhancement of the magnetic and structural phase transition such as martensitic B2 $\rightarrow$ L10 transformation [20]. The Fe-Al binary alloy system also has a phase boundary as seen in its phase diagram and it has been reported that large magnetostriction of $200 \mathrm{ppm}$ was obtained at the composition around the phase boundary [21]. Fe-Pd binary alloys can also show large magnetostriction of up to 
$600 \mathrm{ppm}$ and it has reported that the origin of this large magnetostriction is attributable to rotation of magnetic twins [22-23].

In this study, Fe-Co alloy as an alternative magnetostrictive material was focused on. According to the Slater-Pauling curve, Fe-Co alloy shows the largest number of Bohr magnetons, leading to the largest saturation magnetic flux density among the Fe-, Ni- and Co-based binary alloys [24, 25]. The Fe-Co alloy system is known to possess good magnetic properties, in particular, soft-magnetism [26-29]. Equiatomic $\mathrm{Fe}-\mathrm{Co}$ alloy $\left(\mathrm{Fe}_{50} \mathrm{Co}_{50}\right)$ is significantly brittle, so the Fe-Co- $2 \mathrm{~V}$ alloy $\left(\mathrm{Fe}_{49} \mathrm{Co}_{49} \mathrm{~V}_{2}\right)$, in which a small amount of $\mathrm{V}$ is added to Fe-Co alloy in order to improve ductility, was developed and is called Permendur. Among commercially available soft-magnetic materials, the Fe-Co-2V alloy is known to have the most excellent soft-magnetic properties such as the highest saturation magnetic flux density, high permeability and low core loss [29-31]. Magnetostriction values of a single crystalline equiatomic Fe-Co alloy and a polycrystalline Fe-Co-2V alloy have been reported to be $150 \mathrm{ppm}\left(\lambda_{100}\right)$ [32] and $70 \mathrm{ppm}$ [33], respectively. In 1932, Masiyama studied the magnitude of magnetostriction of Fe-Co binary alloys in a wide composition range and reported that magnetostriction heavily depends on alloy composition and two distinct peaks of magnetostriction were clearly observed, the 1st peak being from around $\mathrm{Fe}_{30} \mathrm{Co}_{70}$ (magnetostriction: $90 \mathrm{ppm}$ ) and the 2nd one being from around $\mathrm{Fe}_{60} \mathrm{Co}_{40}(70 \mathrm{ppm})$ [34]. The phase boundary between the bcc region and the bcc+fcc coexisting region can be seen at a Co content of about 75 at $\%$ in the phase diagram of the Fe-Co binary system [35, 36]. According to the previous report [37], it was said that this phase boundary may enhance the magnetostriction of the Fe-Co alloy in a way similar to enhance the magnetostriction by $\mathrm{D}_{3} / \mathrm{A} 2$ phase boundary in $\mathrm{Fe}-\mathrm{Ga}$ alloy, and indeed, the largest magnetostriction was obtained at a Co content of about 70 at\% in that report. Although some previous studies on the phase diagram of Fe-Co binary alloy system have been conducted by experiments [35] and computer-simulation [36], an accurate phase diagram is still unclear due to very complicated phase precipitations of A1 phase (fcc), A2 phase (disordered bcc) and B2 phase (ordered bcc) in the composition range of 70-90 at\%Co.

Since Hunter et al. [38] reported that thin $\mathrm{Fe}_{34} \mathrm{Co}_{66}$ alloy film showed large magnetostriction of $260 \mathrm{ppm}$, there has been increased interest in the Fe-Co alloy system as a good candidate for a new magnetostrictive alloy. They concluded that a mixture of the bcc phase and the fcc phase should enhance its magnetostriction. The 
magnetic properties of the Fe-Co alloy thin films have been studied for application in MEMS devices [39, 40]. Moreover, if Fe-Co alloy bulk materials actually show large magnetostriction, they can be good candidates for magnetostrictive materials applicable to various actuators and power-generation devices in the future because of their abundance and lower cost as compared with Fe-Ga alloy.

Thus, in this work, Fe-Co binary alloys with Co content higher than 50 at\% were prepared in bulky state by forging and subsequent cold rolling which are often adopted in mass production and then the effect of alloy composition and thermo-mechanical treatment on their microstructure and magnetic properties such as magnetostriction and magnetization were studied.

\section{Experimental Procedure}

Alloy ingots of $\mathrm{Fe}_{1-\mathrm{x}} \mathrm{Co}_{\mathrm{x}}(\mathrm{x}=50,55,60,66,70,75,80,85,90$ at $\%)$ weighing more than $7 \mathrm{~kg}$ were prepared by a high-frequency furnace. The ingots were heated at $1323 \mathrm{~K}$ for $3 \mathrm{~h}$ and then forged into alloy bars. The cross-sectional area of ingots was reduced by half during forging. The reduction rate of forging was $50 \%$. Forging was finished after the temperature of the ingots decreased to $1173-1073 \mathrm{~K}$, and then the ingots were air cooled to room temperature at a cooling rate of a few $\mathrm{K} \cdot \mathrm{s}^{-1}$.

Small specimens were cut out of each alloy ingot to study their microstructure and magnetic properties. The specimen dimensions were about $5 \mathrm{~mm} \times 8 \mathrm{~mm}$ and $0.3-2 \mathrm{~mm}$ in thickness. Some specimens were heat-treated in vacuum at $873-1073 \mathrm{~K}$ for $3 \mathrm{~h}$ and cooled in the furnace to study the effect of annealing temperature on magnetostriction.

After forging, some ingots were cold rolled at room temperature from $10 \mathrm{~mm}$ to $0.3 \mathrm{~mm}$ in thickness in order to compare magnetic properties of the forged alloys to those of the heavily cold-rolled alloys. The rolling reduction rate was $97 \%$. Then small specimens were cut from those cold-rolled sheets and heat treated in vacuum at $1073 \mathrm{~K}$ for $3 \mathrm{~h}$ and cooled in the furnace.

Moreover, each small piece of the forged $\mathrm{Fe}_{25} \mathrm{Co}_{75}, \mathrm{Fe}_{20} \mathrm{Co}_{80}$ and $\mathrm{Fe}_{15} \mathrm{Co}_{85}$ alloy ingots was heated at $1073 \mathrm{~K}$ for $12 \mathrm{~h}$ in vacuum and cooled in the furnace. Those fully-annealed pieces with large amount of the fcc precipitates in the bcc matrix were then cold rolled at room temperature from $10 \mathrm{~mm}$ to $0.3 \mathrm{~mm}$ in thickness. The 
rolling reduction rate was gradually increased from 0 to $20,40,60,80,90,93,95$ and $97 \%$ step by step. Specimens were cut out of the rolled ingots at each step and used for microstructure observation and magnetostriction/magnetization measurements.

Phase identification of the specimens was conducted by X-ray diffraction analysis (hereafter denoted as $\mathrm{XRD} ; \mathrm{Cu}-\mathrm{K} \alpha, 40 \mathrm{kV}$ and $40 \mathrm{~mA}$ ). Microstructure observation of the specimens was conducted by scanning electron microscope-electron backscattering diffraction/oriented imaging microscopy (hereafter denoted as SEM-EBSD/OIM) and transmission electron microscopy (hereafter denoted as TEM) analyses.

Non-magnetic type strain gauges (KFL series, Kyowa Electronic Instruments Co., Ltd.) and special bond (M-Bond610) to fix a strain gauge to the specimen surface were used for magnetostriction measurements. Magnetostriction and saturation magnetization were measured at room temperature in a magnetic field up to $1.2 \mathrm{~T}$ by using a vibrating sample magnetometer (VSM).

The magnetostriction of equiaxed polycrystalline materials can be described by the following equation [6]:

$$
\frac{\Delta l}{l}=\frac{3}{2} \lambda_{s}\left(\cos ^{2} \theta-\frac{1}{3}\right)
$$

$l$ is the length of the specimen. $\lambda_{\mathrm{s}}$ is the measured value of saturation magnetostriction and $\theta$ is the angle between the magnetization direction and the measurement direction. When the magnetostriction is measured parallel to the magnetization direction, that is $\theta=0^{\circ}$, equation (1) is simplified as shown below:

$$
\frac{\Delta l}{l}=\lambda_{s}
$$

Therefore, a magnetic field was applied parallel to the measurement direction of the strain gauge in this study.

\section{Results and Discussion}

\section{3-1. Magnetostriction of the forged Fe-Co alloys}

Figure 1 shows the results of (a) magnetostriction and (b) magnetization measurements of the $\mathrm{Fe}_{1-\mathrm{x}} \mathrm{Co}_{\mathrm{x}}(\mathrm{x}=50,55$, $60,66,70,75,80,85,90$ at $\%$ ) alloys prepared by forging and subsequent annealing at $873-1073 \mathrm{~K}$ for $3 \mathrm{~h}$. The phase diagram of the Fe-Co binary alloy system is superimposed at the upper part of the figure [41]. 
Magnetostriction of the as-forged alloy specimens was around $60 \mathrm{ppm}$ in the composition range of 50-66 at\%Co and increased in the range of 70-75 at\% $\mathrm{Co}$. The as-forged $\mathrm{Fe}_{25} \mathrm{Co}_{75}$ alloy showed the largest magnetostriction up to $108 \mathrm{ppm}$. In the composition range of Co content higher than 75 at\%, magnetostriction decreased drastically and showed a small negative value. In the case of the specimens annealed after forging, magnetostriction was higher than that of the as-forged specimens in the 50-70 at\%Co range. Particularly, in the $60-70$ at\%Co range, magnetostriction increased with increasing annealing temperature. This may be because accumulated dislocations, strain and internal stress were released and grain growth occurred by annealing. Indeed, in the 50-66 at\% Co range, the alloys annealed at $873 \mathrm{~K}$ possess the $\mathrm{B} 2$ ordered structure. In this range, the alloys annealed at $1073 \mathrm{~K}$ also possess the $\mathrm{B} 2$ ordered structure in this study because the cooling rate was low due to furnace cooling although the alloys were annealed at $1073 \mathrm{~K}$ in the A2 disordered region as seen in the phase diagram. There is no difference in crystal structure between the alloys annealed at $873 \mathrm{~K}$ and $1073 \mathrm{~K}$ in this study. So, the factors to increase magnetostriction after annealing in this range should be the microstructure change and the release of dislocations which leads to the release of strain and internal stress. The $\mathrm{Fe}_{30} \mathrm{Co}_{70}$ alloy annealed at $1073 \mathrm{~K}$ showed the largest magnetostriction of $101 \mathrm{ppm}$. However, the $\mathrm{Fe}_{25} \mathrm{Co}_{75}$ alloy is on the bcc/(bcc+fcc) phase boundary, leading to precipitation of the fcc phase during heat-treatment, so the magnetostriction of the annealed $\mathrm{Fe}_{25} \mathrm{Co}_{75}$ alloy was smaller than that of the as-forged alloy. From Fig. 1(a), it can be clearly concluded that magnetostriction showed a maximum in the $\mathrm{Fe}_{25} \mathrm{Co}_{75}$ alloy at around the bcc/(bcc+fcc) phase boundary and that the magnetostriction decreased significantly and then reached 0 or a small negative value in the composition range of $80-90$ at $\%$ Co.

Figure 1(b) indicates the magnetization of the forged alloys. Magnetization tended to decrease with increasing Co content monotonically from about $210 \mathrm{emu} \cdot \mathrm{g}^{-1}$ for $\mathrm{Fe}_{50} \mathrm{Co}_{50}$ alloy to about $175 \mathrm{emu} \cdot \mathrm{g}^{-1}$ for $\mathrm{Fe}_{10} \mathrm{Co}_{90}$ alloy although some scatter is seen. Different from the magnetostriction behavior, magnetization did not change drastically at around the $b c c /(b c c+f c c)$ phase boundary.

Figures 2(a) and (b) show the XRD patterns of the as-forged alloys and the alloys annealed at $1073 \mathrm{~K}$ for $3 \mathrm{~h}$ after forging, respectively. As clearly seen in Fig. 2(a), the alloys with Co content of 50-75 at\% has a single bcc phase while a fcc second phase was slightly precipitated in the $\mathrm{Fe}_{20} \mathrm{Co}_{80}$ alloy. The alloys with $85-90$ at\% Co had a single fcc phase. According to the phase diagram, the coexisting region of the bcc phase and the fcc phase lies in 
the composition range of 75-90 at\%Co. It was thus clear that magnetostriction of the as-forged alloys with Co content more than 75 at\% was very small because of the distinct precipitation of the fcc phase which showed a small negative magnetostriction value. In the case of the alloys annealed after forging shown in Fig. 2(b), the same tendency was obtained but the fcc second phase started to precipitate in the $\mathrm{Fe}_{25} \mathrm{Co}_{75}$ alloy. As a result, the annealed $\mathrm{Fe}_{30} \mathrm{Co}_{70}$ alloy having a single bcc phase showed the largest magnetostriction among the annealed alloys, as shown in Fig. 1(a). It was found that magnetostriction behavior of these alloy specimens corresponded to the bcc and fcc peak appearance behavior in the XRD patterns and the phase diagram.

Figure 3 shows grain mappings obtained from the forged $\mathrm{Fe}_{25} \mathrm{Co}_{75}$ alloy annealed at $1073 \mathrm{~K}$ for $3 \mathrm{~h}$, indicating (a) a microstructure and (b) a phase mapping dividing the fcc phase from the bcc phase. In Fig. 3(b), the dark area and the gray area indicate the bcc main matrix and the fcc second phase, respectively. As seen in Fig. 3(a), the average grain size was around $10 \mu \mathrm{m}$, and it can also be seen in Fig. 3(b) that an fcc phase was precipitated after annealing along the grain boundaries of the bcc main matrix in the annealed $\mathrm{Fe}_{25} \mathrm{Co}_{75}$ alloy.

\section{3-2. Effect of cold rolling on magnetostriction of Fe-Co alloys}

Figure 4(a) shows the results of magnetostriction measurement of the $\mathrm{Fe}_{1-\mathrm{x}} \mathrm{Co}_{\mathrm{x}}(\mathrm{x}=66,70,75,80,85,90$ at\%) alloys prepared by cold-rolling after forging. Magnetostriction of the as-cold rolled alloys was measured both in the rolling direction (RD) and in the direction at the angle of $45^{\circ}$ inclined to RD. It was difficult to cold roll specimens of a near-equiatomic composition range of $\mathrm{x}=50-60$ at $\% \mathrm{Co}$ due to their severe brittleness. $\mathrm{Fe}_{34} \mathrm{Co}_{66}$ alloy was barely able to be cold rolled at room temperature, and the Fe-Co alloys with 70 at\%Co or higher showed good cold rolling workability up to a reduction rate $97 \%$. Cold-rolled specimens possessed higher magnetostriction than the as-forged specimens in the composition range of 66-80 at $\% \mathrm{Co}$ and the as-cold rolled $\mathrm{Fe}_{25} \mathrm{Co}_{75}$ alloy specimen showed the highest magnetostriction of $128 \mathrm{ppm}$ measured parallel to RD among the as-cold rolled alloys. Furthermore, the as-cold rolled $\mathrm{Fe}_{20} \mathrm{Co}_{80}$ alloy specimen showed relatively large magnetostriction of 110 ppm although the as-forged $\mathrm{Fe}_{20} \mathrm{Co}_{80}$ alloy specimen showed a very small value.

In this work, it was found that the magnetostriction measured in the direction at the angle $45^{\circ}$ inclined to $\mathrm{RD}$ was slightly larger than that measured parallel to RD and that the as-cold rolled $\mathrm{Fe}_{25} \mathrm{Co}_{75}$ alloy showed the 
largest magnetostriction up to $140 \mathrm{ppm}$ at the angle $45^{\circ}$. In the similar case, Sugano et al. (1972) reported that the magnetostriction of hot-rolled Fe-Co-2V Permendur alloy was dependent on the measurement angle to RD and showed its maximum value at the angle $45^{\circ}$ [33]. In the case of the specimens cold rolled and subsequently annealed at $1073 \mathrm{~K}$ for $3 \mathrm{~h}$, their magnetostriction decreased with increasing Co content in the composition range of 70-90 at\%Co.

Figure 4(b) shows the results of magnetization measurement of these cold-rolled alloys. Magnetization tended to decrease with increasing Co content, and detailed observation also revealed that the magnetization of the as-cold rolled alloys measured in the direction at the angle $45^{\circ}$ inclined to $\mathrm{RD}$ was slightly larger than that measured parallel to $\mathrm{RD}$ in the composition range of $66-80$ at\% $\mathrm{Co}$.

Figures 5(a) and (b) show the XRD patterns of the as-cold rolled alloys and the alloys annealed at $1073 \mathrm{~K}$ for $3 \mathrm{~h}$ after cold-rolling, respectively. The as-cold rolled alloys with $66-75$ at\%Co had a single bcc phase as did the as-forged alloys. The as-cold rolled $\mathrm{Fe}_{20} \mathrm{Co}_{80}$ alloy also possessed a single bcc phase while the as-forged $\mathrm{Fe}_{20} \mathrm{Co}_{80}$ alloy possessed both the bcc main phase and the fcc second phase. It was thus conceivable by XRD observations that the fcc phase in the $\mathrm{Fe}_{20} \mathrm{Co}_{80}$ alloy disappeared by severe cold rolling, which means that the bcc/(bcc+fcc) phase boundary shifts to higher Co content. In 1936, Nishiyama reported that the Stainless Invar (Co-36Fe-8.7Cr alloy) showed the strain-induced martensite transformation from $\gamma$ phase (fcc structure) to $\alpha$ phase (bcc structure) [42]. So, the Fe-Co alloy with relatively small amount of fcc phase precipitation may show the transformation from the fcc phase to the bcc phase by heavy deformation in a similar manner, resulting in the disappearance of the fcc phase. Therefore, the as-cold rolled $\mathrm{Fe}_{20} \mathrm{Co}_{80}$ alloy was in a single bcc state, with the result that the alloy showed relatively large magnetostriction of more than $110 \mathrm{ppm}$. With higher Co content, the as-cold rolled $\mathrm{Fe}_{15} \mathrm{Co}_{85}$ alloy showed distinct peaks originating from the fcc single phase and its magnetostriction decreased drastically, as shown in Fig. 4(a). It seems that the strain introduced into the alloys with 85 at\% Co and over was not enough to promote the martensite transformation, the bcc distinct peaks did not appear in Fig. 5(a). In the case of the annealed specimens shown in Fig. 5(b), the largest magnetostriction of $110 \mathrm{ppm}$ was obtained in the $\mathrm{Fe}_{30} \mathrm{Co}_{70}$ alloy having a bcc single phase. As mentioned above, the magnetostriction of the specimens annealed after cold rolling decreased with increasing Co content in the composition range of 70-90 at\%Co. According to Fig. 5(b), this is because those 
annealed alloys having 75-90 at\% Co are around the $\mathrm{bcc} /(\mathrm{bcc}+\mathrm{fcc})$ phase region, resulting that the amount of precipitated fcc phase in the alloys increases gradually with increasing Co content.

Besides the XRD observations, the microstructure of the as-cold rolled $\mathrm{Fe}_{25} \mathrm{Co}_{75}$ alloy was observed by using the SEM-EBSD/OIM system in order to understand the reasons for the dependence of magnetostriction on the measurement angle to RD.

Figures 6(a) and (b) show the microstructure mapping and the inversed pole figures of the as-cold rolled $\mathrm{Fe}_{25} \mathrm{Co}_{75}$ alloy having the largest magnetostriction in this work. The characteristic texture is formed by severe cold-rolling, as clearly shown in Fig. 6(a), which is a typical stripe microstructure obtained by cold rolling with an average grain size of about $2.5 \mu \mathrm{m}$. Figure $6(\mathrm{~b})$ clearly shows the features of the characteristic microstructure obtained in this alloy, namely, a distinct texture with crystallographic low Miller index planes scattering from (101) plane to (112) plane normal to RD, from (001) plane to (111) plane normal to surface (NS) and also from (101) plane to (111) plane normal to both RD and NS. This means that there are a large number of grains whose (101) plane is normal to $\mathrm{RD}$, with the result that there are a number of grains in which the axis of easy magnetization $<100>$ turns toward the direction at the angle of $45^{\circ}$ inclined to RD. Thus, it is conceivable that the magnetization and magnetostriction measured at the angle of $45^{\circ}$ to $\mathrm{RD}$ are higher than those measured parallel to RD. In previous papers, it has been reported that a heavily rolled equiatomic FeCo alloy formed the $\{100\}<011>$ texture $[43,44]$. In this work, a similar microstructure was obtained after severe cold rolling.

As you can see in Fig. 1(a), the magnetostriction of the forged alloys increased after annealing in the 50-70 at\% Co range. However, the cold-rolled $\mathrm{Fe}_{34} \mathrm{Co}_{66}$ and $\mathrm{Fe}_{30} \mathrm{Co}_{70}$ alloys showed the decrease in magnetostriction after annealing. This may be because the distinct texture formed by heavy cold rolling became broad during heat-treatment and this leads to the decrease in magnetostriction in the cold-rolled and subsequently annealed $\mathrm{Fe}_{34} \mathrm{Co}_{66}$ and $\mathrm{Fe}_{30} \mathrm{Co}_{70}$ alloys while the accumulated dislocations, strain and internal stress were released and the grain growth occurred during heat-treatment, leading to the increase in magnetostriction in the forged and subsequently annealed alloys.

\section{3-3. Effect of reduction rate on magnetostriction of cold-rolled Fe-Co alloys}


$\mathrm{Fe}_{25} \mathrm{Co}_{75}, \mathrm{Fe}_{20} \mathrm{Co}_{80}$ and $\mathrm{Fe}_{15} \mathrm{Co}_{85}$ forged alloys were fully annealed at $1073 \mathrm{~K}$ for $12 \mathrm{~h}$ and then cooled in a furnace. The annealed alloy specimens were cold rolled stepwise from $10 \mathrm{~mm}$ (reduction rate $0 \%)$ to $8 \mathrm{~mm}(20 \%)$ $\rightarrow 6 \mathrm{~mm}(40 \%) \rightarrow 4 \mathrm{~mm}(60 \%) \rightarrow 2 \mathrm{~mm}(80 \%) \rightarrow 1 \mathrm{~mm}(90 \%) \rightarrow 0.7 \mathrm{~mm}(93 \%) \rightarrow 0.5 \mathrm{~mm}(95 \%) \rightarrow 0.3 \mathrm{~mm}$ $(97 \%)$ in thickness. The XRD observations and the magnetostriction/magnetization measurements were conducted at each reduction rate. As for the magnetostriction measurements, a strain gauge was fixed on the specimen surface parallel to RD when the rolled alloy was thin $(\leq 2 \mathrm{~mm}$ in thickness). When the alloy was thick $(\geq 4 \mathrm{~mm})$, a strain gauge was fixed to a sliced cross-section normal to RD.

Figure 7(a) shows the magnetostriction as a function of the reduction rate of cold-rolling. The magnetostriction of $\mathrm{Fe}_{25} \mathrm{Co}_{75}$ alloys with reduction rate up to $60 \%$ was almost $70 \mathrm{ppm}$. With a larger reduction rate, the magnetostriction increased significantly and reached $120 \mathrm{ppm}$ at a reduction rate of $95 \%$. In the case of the $\mathrm{Fe}_{20} \mathrm{Co}_{80}$ alloys with a reduction rate larger than $60 \%$, the magnetostriction increased drastically and reached 105 ppm at a reduction rate of $97 \%$. These alloys were found to show a significant increase in magnetostriction by heavy cold-rolling. On the contrary, the $\mathrm{Fe}_{15} \mathrm{Co}_{85}$ alloys showed a small negative value regardless of the reduction rate.

Figure 7(b) shows the magnetization as a function of the reduction rate. As can be seen in the figure, the magnitude of magnetization remained almost constant in all the alloys subjected to cold rolling at $0-80 \%$ although some scatter was observed. The magnetization thus increased slightly with increasing reduction rate higher than $90 \%$ as well as the magnetostriction.

Figure 8(a) shows the variations of the XRD pattern of the gradually cold-rolled $\mathrm{Fe}_{25} \mathrm{Co}_{75}$ alloys as a function of the reduction rate. The observation range was $2 \theta=43-47^{\circ}$. In this $2 \theta$ region, two distinct peaks from the bcc (110) plane and the fcc (111) plane were observed. It can be seen in the figure that the intensity of the fcc peak decreased with increasing reduction rate and that the fcc peak almost disappeared after heavy rolling at a reduction rate of $90 \%$ and over. Therefore, it is conceivable that the increase in magnetostriction at the higher reduction rate was attributable to both the decrease in the fraction of the fcc phase and to the formation of texture which was shown in Fig. 6.

Figures $8(\mathrm{~b})$ and (c) show the variations of the XRD pattern of the gradually cold-rolled $\mathrm{Fe}_{20} \mathrm{Co}_{80}$ and 
$\mathrm{Fe}_{15} \mathrm{Co}_{85}$ alloys, respectively. Figure 8(b) indicates that the intensity of the fcc peak in the $\mathrm{Fe}_{20} \mathrm{Co}_{80}$ alloys as well as that of the $\mathrm{Fe}_{25} \mathrm{Co}_{75}$ alloys gradually decreased with increasing reduction rate, leading to a significant increase in magnetostriction. In the case of the $\mathrm{Fe}_{15} \mathrm{Co}_{85}$ alloys shown in Fig. 8(c), the bcc peak which should appear at around $2 \theta=45.3^{\circ}$ was not observed and the intensity of the fcc peak at around $2 \theta=44^{\circ}$ did not decrease even after heavy cold-rolling up to $97 \%$. So, it was concluded that the magnetostriction of the cold-rolled $\mathrm{Fe}_{15} \mathrm{Co}_{85}$ alloys was always a small negative value because the alloy was in a fcc single state after heavy cold rolling.

Figure 9 shows TEM observations of the $\mathrm{Fe}_{20} \mathrm{Co}_{80}$ alloys subjected to cold rolling at reduction rates of 0\%, 60\% and 97\%, the magnetostriction values of which are shown in Fig. 7. Figures 9(a), (c) and (e) are the bright field images and (b), (d) and (f) are selected area diffraction rings with the indices. The grain size was found to decrease with increasing reduction rate and, moreover, a layered texture was formed after severe rolling at $97 \%$. As seen in Fig. 9(b), distinct spots originating from the bcc phase and the fcc phase were observed in the diffraction rings. The intensity of those fcc spots decreased with increasing reduction rate. Finally, the spots for the fcc phase disappeared in the specimen cold rolled at $97 \%$, as shown in Fig. 9(f), in a way similar to that in Fig. 8(b), due to the strain-induced martensite transformation [42].

It should be also noted that the grain sizes estimated by SEM-EBSD/OIM were much larger than the grain size seen directly in the TEM images. Because the measurement accuracy of the SEM-EBSD/OIM depends on the step size by which the pseudo-Kikuchi patterns are obtained from the sample surface.

In some previous papers, magnetostriction of the Fe-Co alloy was reported to be enhanced at around the $\mathrm{bcc} /(\mathrm{bcc}+\mathrm{fcc})$ phase boundary $[37,38]$. Indeed, in this work, the largest magnetostriction was obtained in the $\mathrm{Fe}_{25} \mathrm{Co}_{75}$ alloy which was located at around the bcc/(bcc+fcc) phase boundary in the phase diagram. However, the role of the fcc phase in enhancing or degrading magnetostriction is not yet clear. At least, it was found in this study that the distinct appearance of the fcc phase really caused the magnetostriction to deteriorate. Hunter et al. have reported that the volume fraction of the fcc phase was $0.3 \%$ in the $\mathrm{Fe}_{34} \mathrm{Co}_{66}$ alloy thin film which showed a large magnetostriction of $260 \mathrm{ppm}$ [38]. It seems that detection of the fcc phase with its volume fraction of $0.3 \%$ may be difficult by XRD nor by conventional TEM.

At any rate, the magnetostriction of the bulky Fe-Co binary alloys prepared by forging and subsequent 
heavy cold rolling was investigated in this study. As results, it was found that $\mathrm{Fe}_{25} \mathrm{Co}_{75}$ alloy which lies just around the two phase boundary $(\mathrm{bcc} /(\mathrm{bcc}+\mathrm{fcc}))$ showed the largest magnetostriction up to $140 \mathrm{ppm}$ by cold rolling and that the fcc phase precipitated in the alloys disappeared by heavy cold rolling, leading to being a single bcc phase in the alloys. Furthermore, a distinct texture was formed in the alloys by heavy cold rolling. In this study, it was concluded that these two factors contributed to the increase in magnetostriction in the as-cold rolled $\mathrm{Fe}_{25} \mathrm{Co}_{75}$ alloy.

\section{Conclusions}

In this work, the $\mathrm{Fe}_{1-\mathrm{x}} \mathrm{Co}_{\mathrm{x}}(\mathrm{x}=50,55,60,66,70,75,80,85,90$ at $\%)$ alloys were prepared by forging and subsequent cold rolling. Microstructure, magnetostriction and magnetization of the alloys in bulky state were studied as functions of alloy compositions and thermomechanical treatments. Results obtained in this work are as follows.

1. Magnetostriction of the as-forged alloys was about $60 \mathrm{ppm}$ in the composition range of 50-66 at $\%$. It increased with increasing $\mathrm{Co}$ content up to 75 at $\%$ and the as-forged $\mathrm{Fe}_{25} \mathrm{Co}_{75}$ alloy reached the largest value of about 108 ppm among the as-forged alloys. The as-forged alloy with the Co content of $80 \%$ and over showed a small negative value. In the case of the alloys annealed after forging, the $\mathrm{Fe}_{30} \mathrm{Co}_{70}$ alloy showed the largest magnetostriction of 101 ppm among the annealed alloys. With higher Co content, magnetostriction drastically decreased and showed a small negative value.

2. The magnetostriction of the as-cold rolled Fe-Co alloys was larger than that of the forged alloys and was dependent on the measurement angle to the rolling direction (RD). The as-cold rolled $\mathrm{Fe}_{25} \mathrm{Co}_{75}$ alloy showed relatively large magnetostriction of $128 \mathrm{ppm}$ measured parallel to RD. With higher Co content, the magnetostriction decreased, and the as-cold rolled $\mathrm{Fe}_{15} \mathrm{Co}_{85}$ alloy did not possess any effective magnetostriction. The magnetostriction measured at an angle of $45^{\circ}$ to $\mathrm{RD}$ was larger than that measured parallel to RD and reached 140 ppm at maximum in the as-cold rolled $\mathrm{Fe}_{25} \mathrm{Co}_{75}$ alloy. This is because the as-cold rolled alloy possessed a nearly $\{100\}<011>$ texture, which means the RD is nearly parallel to the crystallographic orientation $<011>$ of grains, resulting in the axis of easy magnetization $<001>$ being at the angle of $45^{\circ}$ to RD. When the as-cold rolled alloys were annealed, the magnetostriction of those annealed alloys became lower than that of the as-cold rolled alloys. In 
particular, the annealed alloys with 70 at\% Co and over showed a monotonical decrease in magnetostriction with increasing Co content due to fcc phase precipitation.

3. Magnetization of both the Fe-Co forged and cold-rolled alloys showed a tendency to decrease with increasing Co content. From detailed comparison, it was also found that the magnetization of the cold-rolled alloys was slightly larger than that of the forged alloys.

4. The $\mathrm{Fe}_{25} \mathrm{Co}_{75}$ and $\mathrm{Fe}_{20} \mathrm{Co}_{80}$ alloys fully annealed after forging were gradually cold rolled and then magnetostriction and magnetization were measured. Results indicated that the magnetostriction of the cold-rolled $\mathrm{Fe}_{25} \mathrm{Co}_{75}$ and $\mathrm{Fe}_{20} \mathrm{Co}_{80}$ alloys at the reduction rate of $0-60 \%$ was not changed but that of the alloys significantly increased with increasing reduction rate from $60 \%$ to $97 \%$. According to the XRD and TEM observations, the non-rolled alloys possessed both the bcc and the fcc phases, the intensity of the fcc peak decreased and disappeared with increasing reduction rate. The alloy changed to a bcc single state at the reduction rate of higher than $90 \%$, probably leading to an increase in magnetostriction.

\section{Acknowledgement}

This study was partially supported by the Revitalization Promotion Project (2012-2014, H24SEN II-35) of the Japan Science and Technology Agency (JST) and by the six-university collaboration project on Advanced Materials Development and Integration of Novel Structured Metallic and Inorganic Materials supported by the Ministry of Education, Culture, Sports, Science and Technology of Japan (MEXT). The authors would like to express their deepest appreciation to Dr. R.Y. Umetsu and Mr. K. Abe for their technical help in preparing alloy samples and in measurement of magnetostriction. 


\section{References}

1. A. Ludwig, E. Quandt, J. Appl. Phys. 87 (2000) 4691-4695.

2. D. Niarchos, Sens. Actuators A 106 (2003) 255-262.

3. M.R. Gibbs, E.W. Hill, P.J. Wright, J. Phys. D 37 (2004) R237-R244.

4. D.J. Bell, T.J. Lu, N.A. Fleck, S.M. Spearing, J. Micromech. Microeng. 15 (2005) S153-S164.

5. L. Wang, F.G. Yuan, Smart Mater. Struct. 17 (2008) 045009.

6. A.E. Clark and H. Eda, Giant magnetostrictive materials, Nikkan Kogyo Publishing (1995).

7. J.H. Liu, C.B. Jiang, H.B. Xu, Science China Technological Sciences, 55 (2012) 1319-1326.

8. H. Szymczak, J. Magn. Magn. Mater. 200 (1999) 425-438.

9. H. Uchida, Y. Matsumura, H. Uchida, H. Kaneko, J. Magn. Magn. Mater. 239 (2002) 540-545.

10. N.C. Koon, C.M. Williams, B.N. Das, J. Magn. Magn. Mater. 100 (1991) 173-185.

11. K.B. Hathaway, A.E. Clark, MRS Bulletin 18 (1993) 34-41.

12. A.G. Olabi, A. Grunwald, Mater. Design 29 (2008) 469-483.

13. S. Yang, H. Bao, C. Zhou, Y. Wang, X. Ren, Y. Matsushita, Y. Katsuya, M. Tanaka, K. Kobayashi, X. Song, J. Gao, Phys. Rev. Lett. 104 (2010) 197201.

14. V.H. Babu, G. Markandeyulu, A. Subrahmanyam, Appl. Phys. Lett. 90 (2007) 252513.

15. N. Srisukhumbowornchai, S. Guruswamy, J. Appl. Phys. 90 (2001) 5680-5688.

16. T. Takahashi, K. Hashimoto, T. Okazaki, Y. Furuya, T. Kubota, C. Saito, Scripta Mater. 60 (2009) 847-849.

17. A.E. Clark, K.B. Hathaway, M. Wun-Fogle, J.B. Restorff, T.A. Lograsso, V.M. Keppens, G. Petculescu, R.A. Taylor, J. Appl. Phys. 93 (2003) 8621-8623.

18. E.M. Summers, T.A. Lograsso, M. Wun-Fogle, J. Mater. Sci. 42 (2007) 9582-9594.

19. H. Cao, P.M. Gehring, C.P. Devreugd, J.A. Rodriguez-Rivera, J. Li, D. Viehland, Phys. Rev. Lett. 102 (2009) 127201.

20. J. Boisse, H. Zapolsky, A.G. Khachaturyan, Acta Mater. 59 (2011) 2656-2668.

21. A.E. Clark, J.B. Restorff, M. Wun-Folge, D. Wu, T.A. Lograsso, J. Appl. Phys. 103 (2008) 07B310.

22. T. Kubota, T. Okazaki, Y. Furuya, T. Watanabe, J. Magn. Magn. Mater. 239 (2002) 551-553.

23. H. Yabe, Y. Nishi, Jpn. J. Appl. Phys. 42 (2003) 96-99.

24. J.C. Slater, Phys. Rev. 49 (1936) 537-545.

25. L. Pauling, Phys. Rev. 54 (1938) 899-904.

26. T. Sourmail, Progr. Mater. Sci. 50 (2005) 816-880.

27. R.S. Srivastava, J. Appl. Phys. 48 (1977) 1355-1358.

28. S.N. Piramanayagam, M.J. Liau, J.Z. Shi, B.C. Lim, J. Magn. Magn. Mater. 303 (2006) e152-e155.

29. R.S. Sundar, S.C. Deevi, Int. Mater. Rev. 50 (2005) 157-192. 
30. K. Kawahara, J. Mater. Sci. 18 (1983) 1709-1718.

31. K. Kawahara, J. Mater. Sci. 18 (1983) 3437-3448.

32. R.C. Hall, J. Appl. Phys. 31 (1960) S157-S158.

33. M. Sugano, Y. Sato, F. Hirama, K. Numakura, Soc. Mater. Sci. Japan 21 (1972) 260-266.

34. Y. Masiyama, The Science Reports of the Tohoku Imperial University, 1st series, 21 (1932), 394-410.

35. Y. Ustinovshikov, B. Pushkarev, J. Alloy. Comp. 424 (2006) 145-151.

36. I. Ohnuma, H. Enoki, O. Ikeda, R. Kainuma, H. Ohtani, B. Sundman, K. Ishida, Acta Mater. 50 (2002) 379-393.

37. L. Dai, M. Wuttig, unpublished work (Department of Mat. Sci. \& Eng., University of Maryland, 2007).

38. D. Hunter, W. Osborn, K. Wang, N. Kazantseva, J. Hattrick-Simpers, R. Suchoski, R. Takahashi, M.L. Young, A. Mehta, L.A. Bendersky, S.E. Lofland, M. Wuttig, I. Takeuchi, Nat. Comm. 2 (2011) 518.

39. M.D. Cooke, L-C. Wang, R. Watts, R. Zuberek, G. Heydon, W.M. Rainforth, G.A. Gehring, J. Phys. D: Appl. Phys. 33 (2000) 1450-1459.

40. T. Nakajima, T. Takeuchi, I. Yuito, K. Kato, M. Saito, K. Abe, T. Sasaki, T. Sekiguchi, S. Yamaura, Mater. Trans. 55 (2014) 556-560.

41. M. Hansen and K. Anderko, Constitution of Binary Alloys, McGraw-Hill (1958).

42. Z. Nishiyama, The Science Reports of the Tohoku Imperial University, 1st series, 25 (1936) 94-103.

43. J.N. Deng, E. Bouzy, J.J. Fundenberger, R.L. Peng, C.S. He, D.Z. Zhang, Y.D. Wang, Mater. Sci. For. $495-497$ (2005) 731-736.

44. J. Deng, Y. Yang, Y. Wang, J. Chen, R. Peng, C. Yuan, E. Bouzy, J.J. Fundenberger, J. Mater. Sci. Technol. 25 (2009) 219-224. 


\section{Figure captions}

Figure 1

Magnetostriction (a) and saturation magnetization (b) of forged and subsequently annealed Fe-Co alloys as a function of Co content with the phase diagram indicated in the upper part of the figure. Solid circles: as-forged; open circles: forged and subsequently annealed at $873 \mathrm{~K}$; open squares: forged and subsequently annealed at $973 \mathrm{~K}$ and open triangles: forged and subsequently annealed at $1073 \mathrm{~K}$.

Figure 2 XRD patterns of Fe-Co alloys forged and subsequently annealed at $1073 \mathrm{~K}$. (a) as-forged and (b) annealed after forging.

Figure 3 Microstructure of the $\mathrm{Fe}_{25} \mathrm{Co}_{75}$ alloy sample forged and subsequently annealed at $1073 \mathrm{~K}$ for $3 \mathrm{~h}$. (a) microstructure and (b) two phase mapping indicating the fcc phase precipitation maybe along grain boundaries of the bcc matrix.

Figure 4 Magnetostriction (a) and saturation magnetization (b) of cold-rolled Fe-Co alloys, measured both in the directions parallel to RD and the $45^{\circ}$ incline to RD. Solid circle: as-cold rolled, measured parallel to RD, Solid triangle: as-cold rolled, measured at the angle $45^{\circ}$ inclined to RD and Open triangle: cold-rolled and subsequently annealed at $1073 \mathrm{~K}$, measured parallel to RD.

Figure 5 XRD patterns of Fe-Co alloys forged and then cold rolled. (a) as-rolled and (b) annealed after rolling.

Figure $6 \quad$ Microstructure (a) and inverse pole figures (b) obtained from an as-cold rolled $\mathrm{Fe}_{25} \mathrm{Co}_{75}$ alloy sheet.

Figure $7 \quad$ Magnetostriction (a) and saturation magnetization (b) of cold-rolled Fe-Co alloys as a function of rolling reduction rate.

Figure 8 Variations of XRD pattern of a cold-rolled Fe25Co75 alloy, heavily depending on rolling reduction rate. (a) $\mathrm{Fe}_{25} \mathrm{Co}_{75}$, (b) $\mathrm{Fe}_{20} \mathrm{Co}_{80}$ and (c) $\mathrm{Fe}_{15} \mathrm{Co}_{85}$ alloys.

Figure 9

TEM observations of the $\mathrm{Fe}_{20} \mathrm{Co}_{80}$ alloy subjected to cold rolling at $0 \%, 60 \%$ and $97 \%$. (a), (c), 
(e) are bright field images and (b), (d), (f) are selected area diffraction rings. 
Figure 1

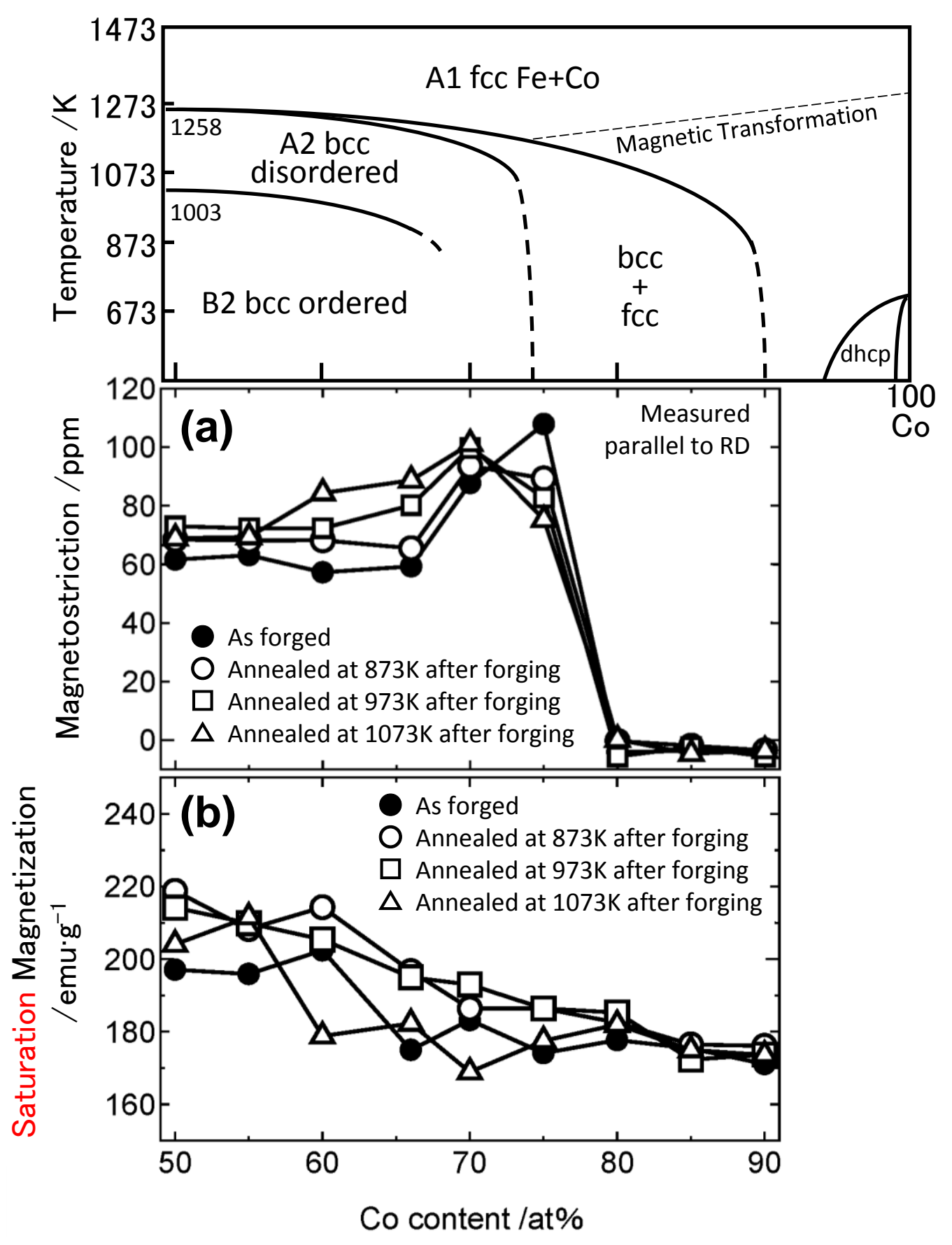



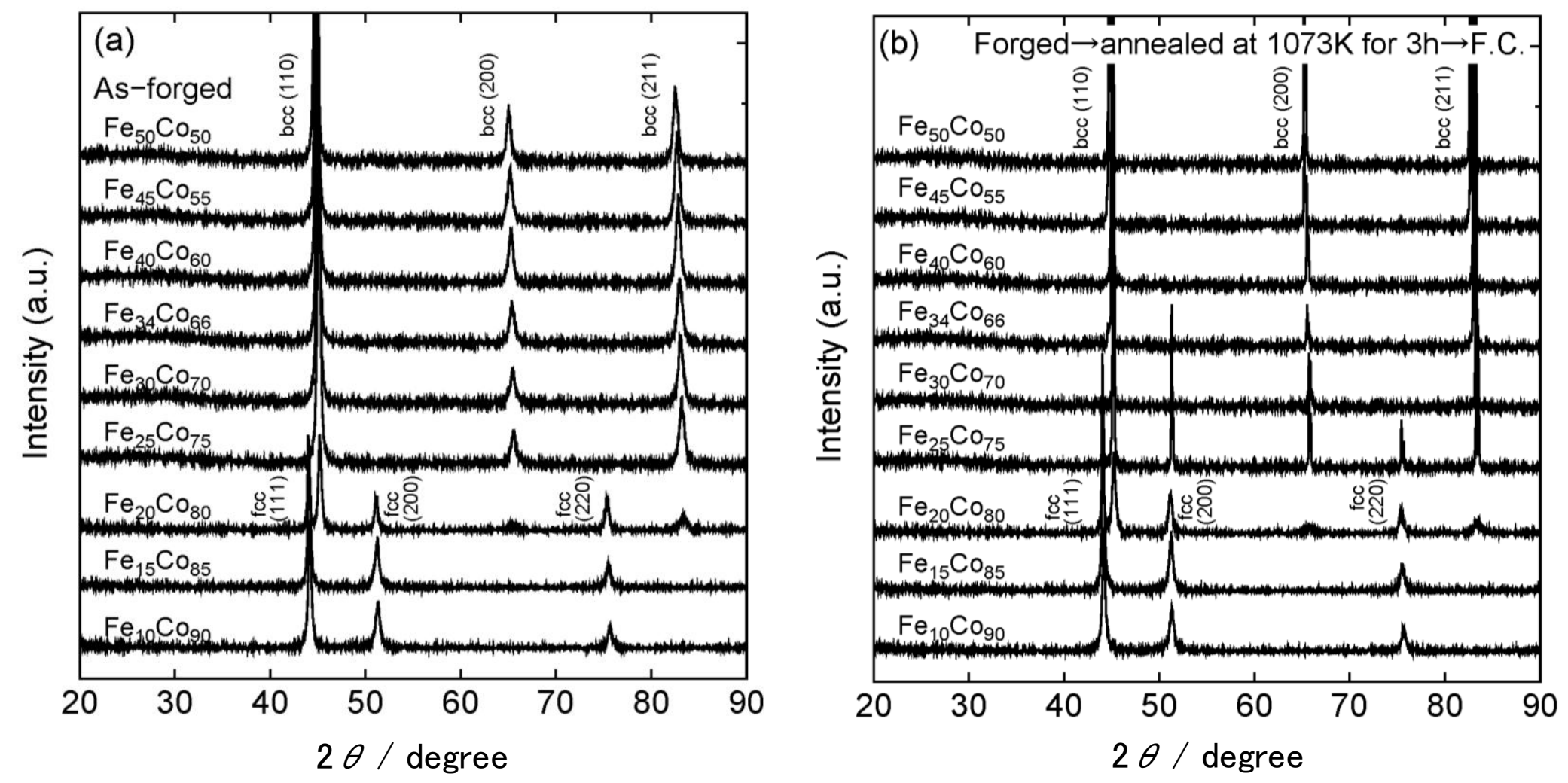

Figure 2 

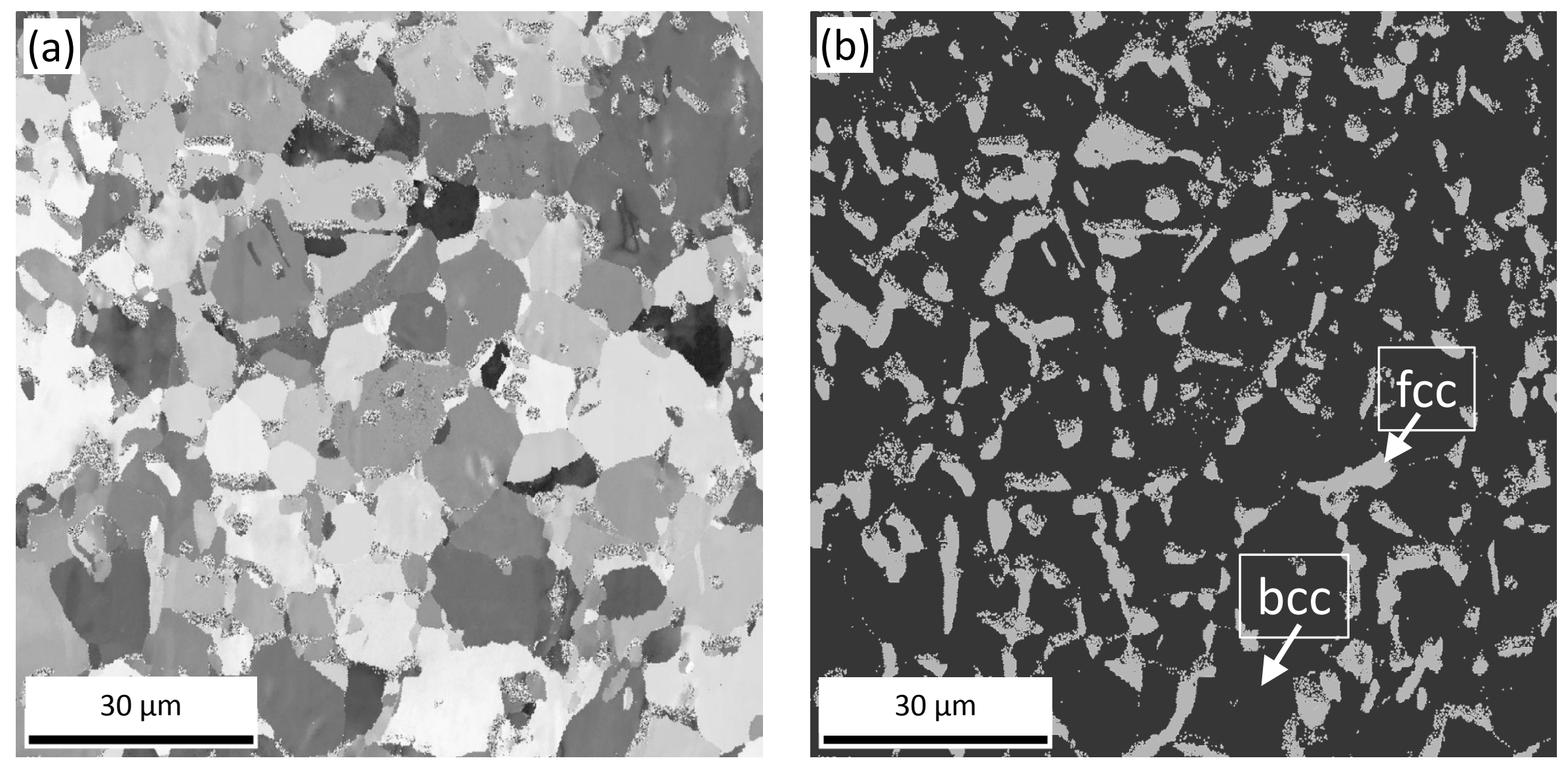

Figure 3 


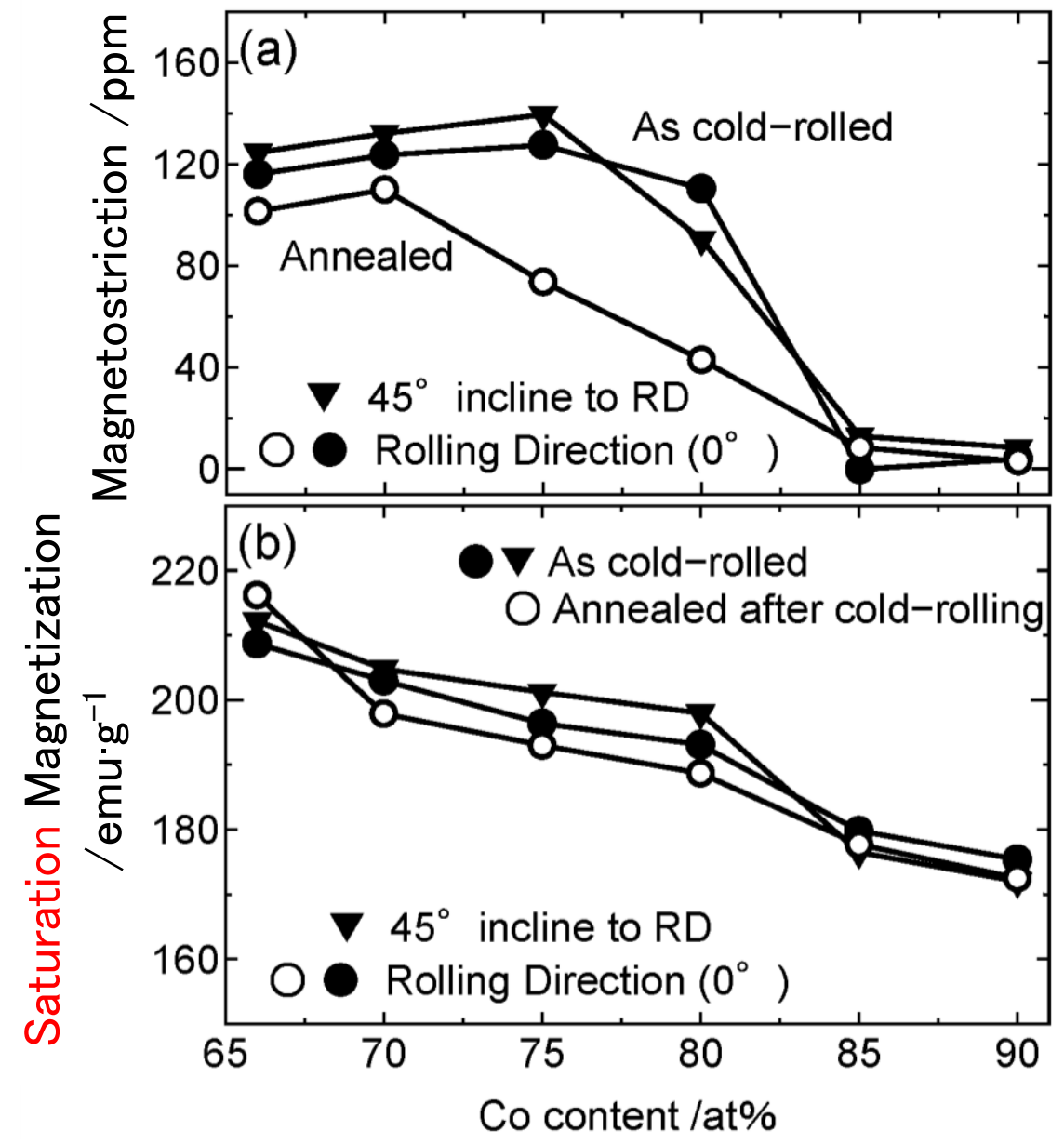

Figure 4 

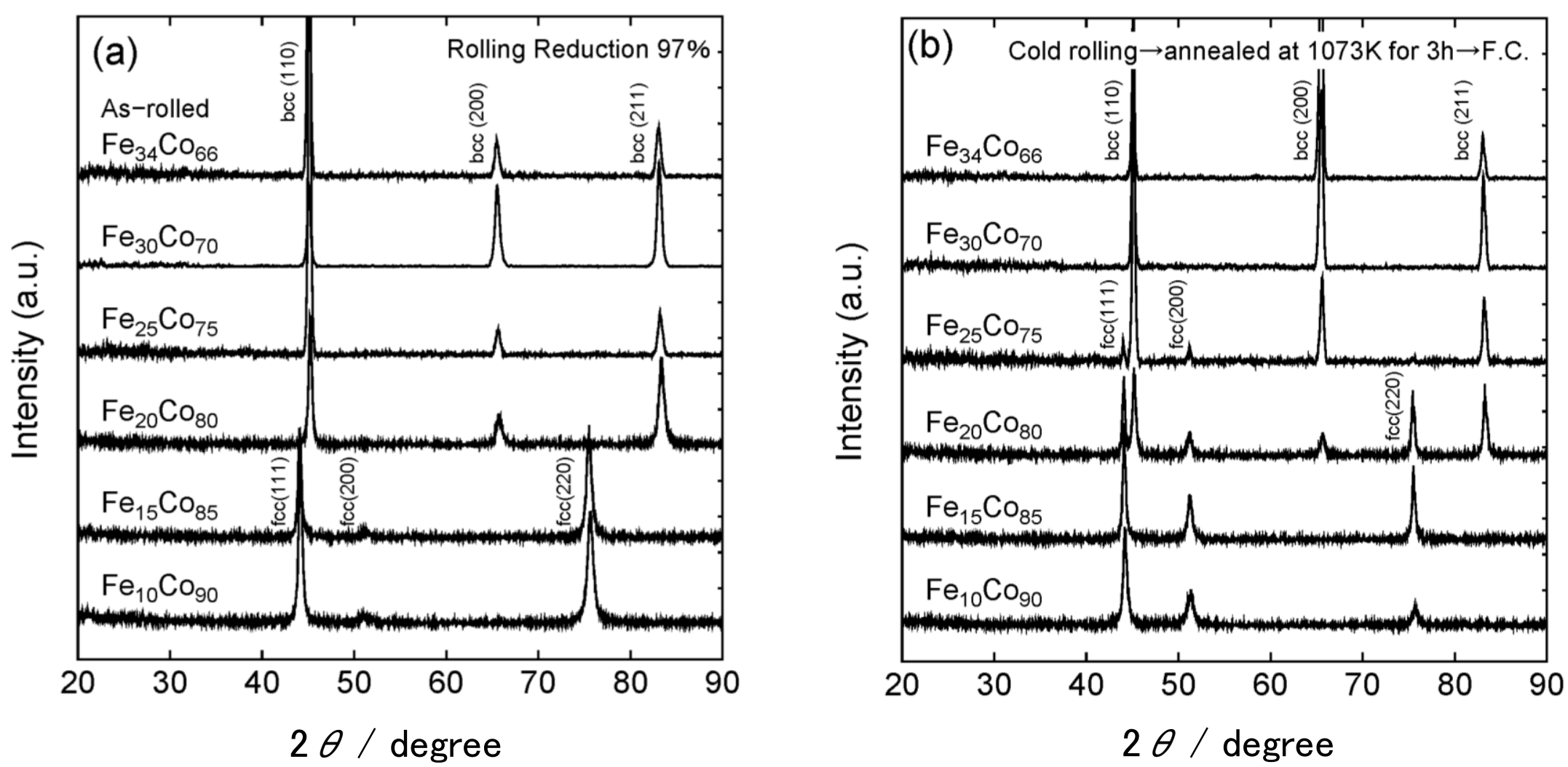

Figure 5 


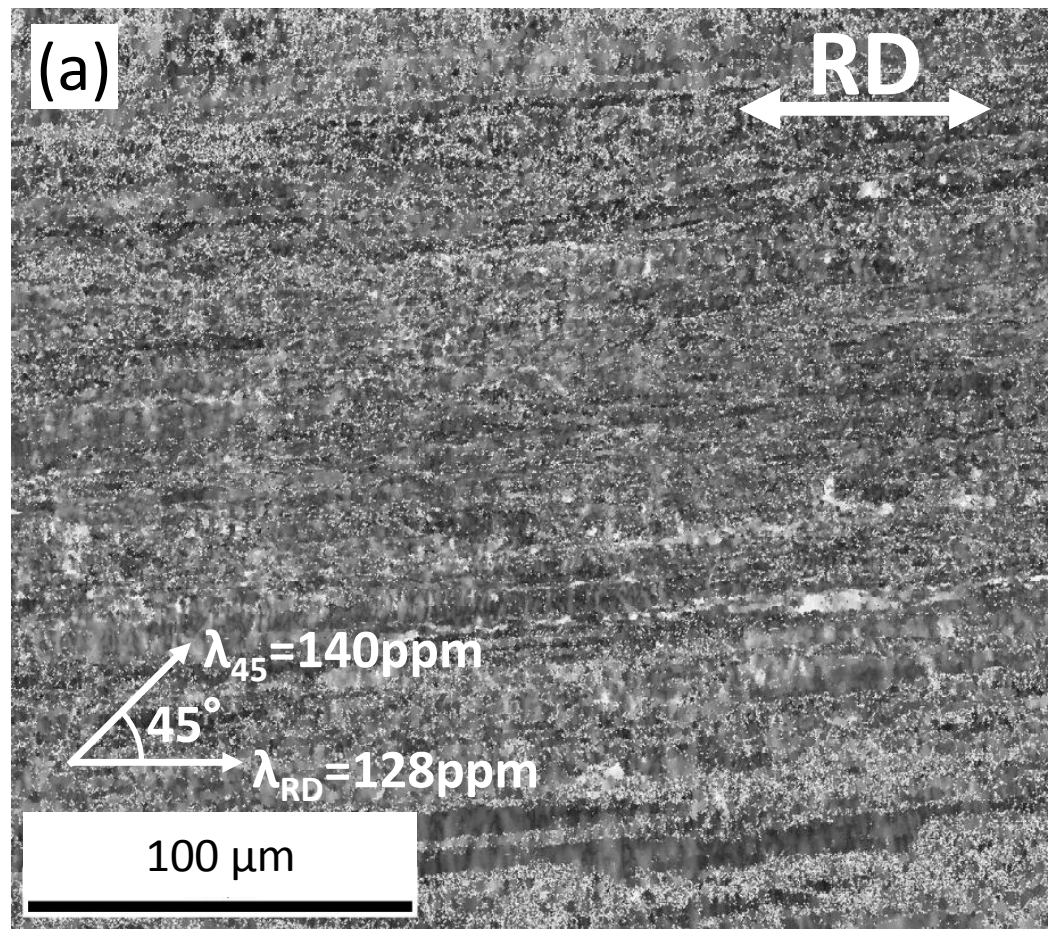

Figure 6(a) 

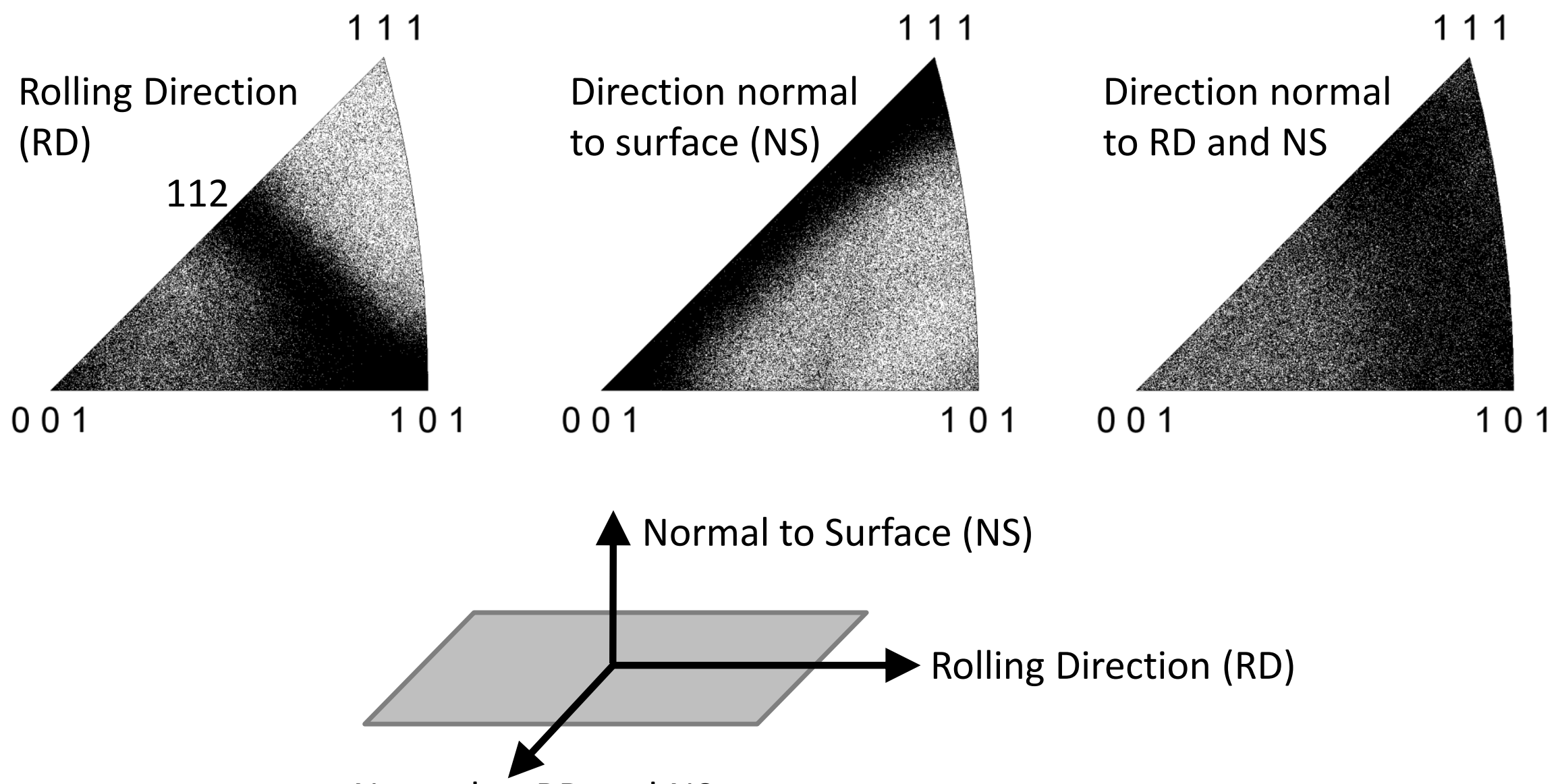

Normal to RD and NS

Figure 6(b) 


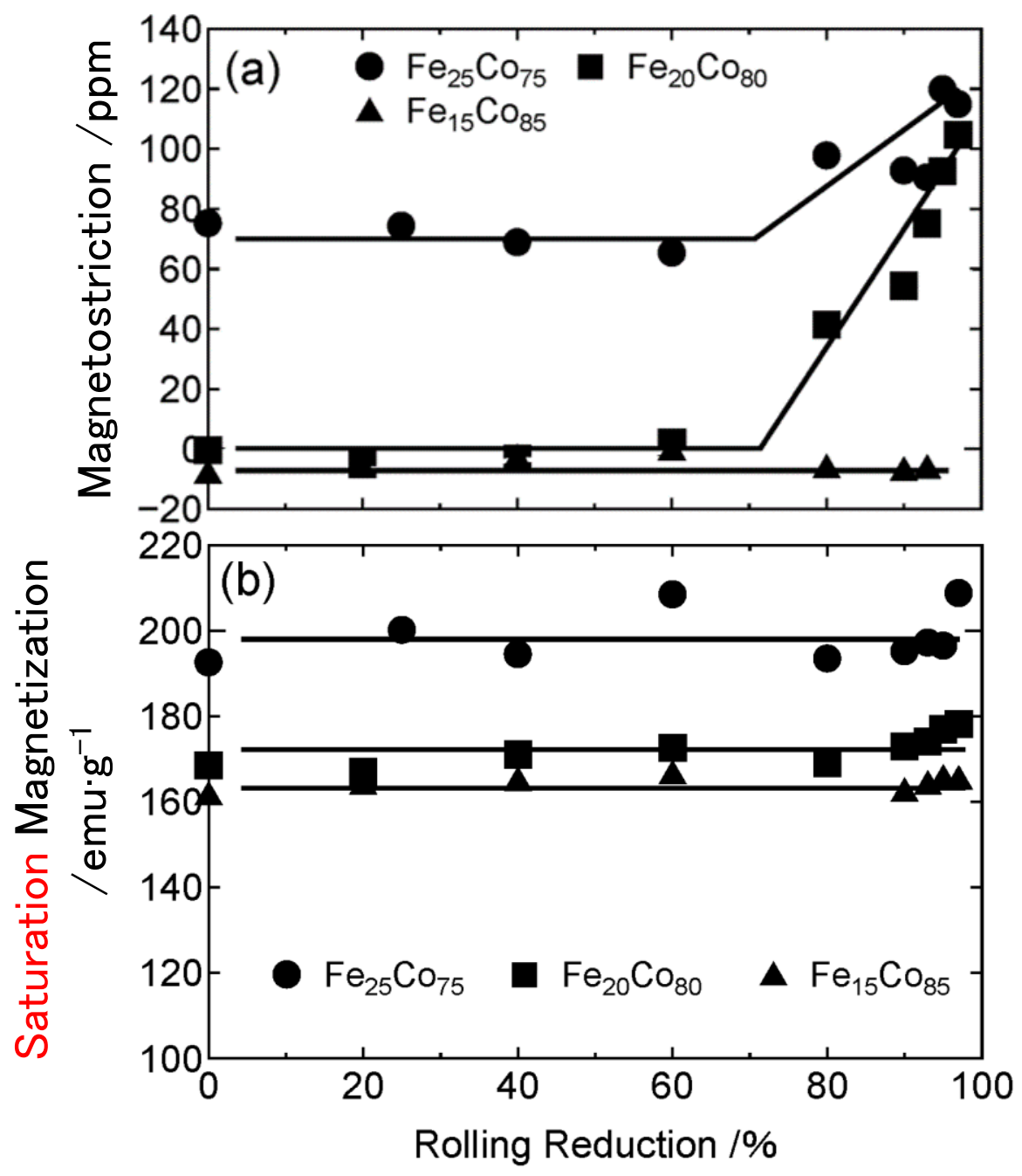

Figure 7 


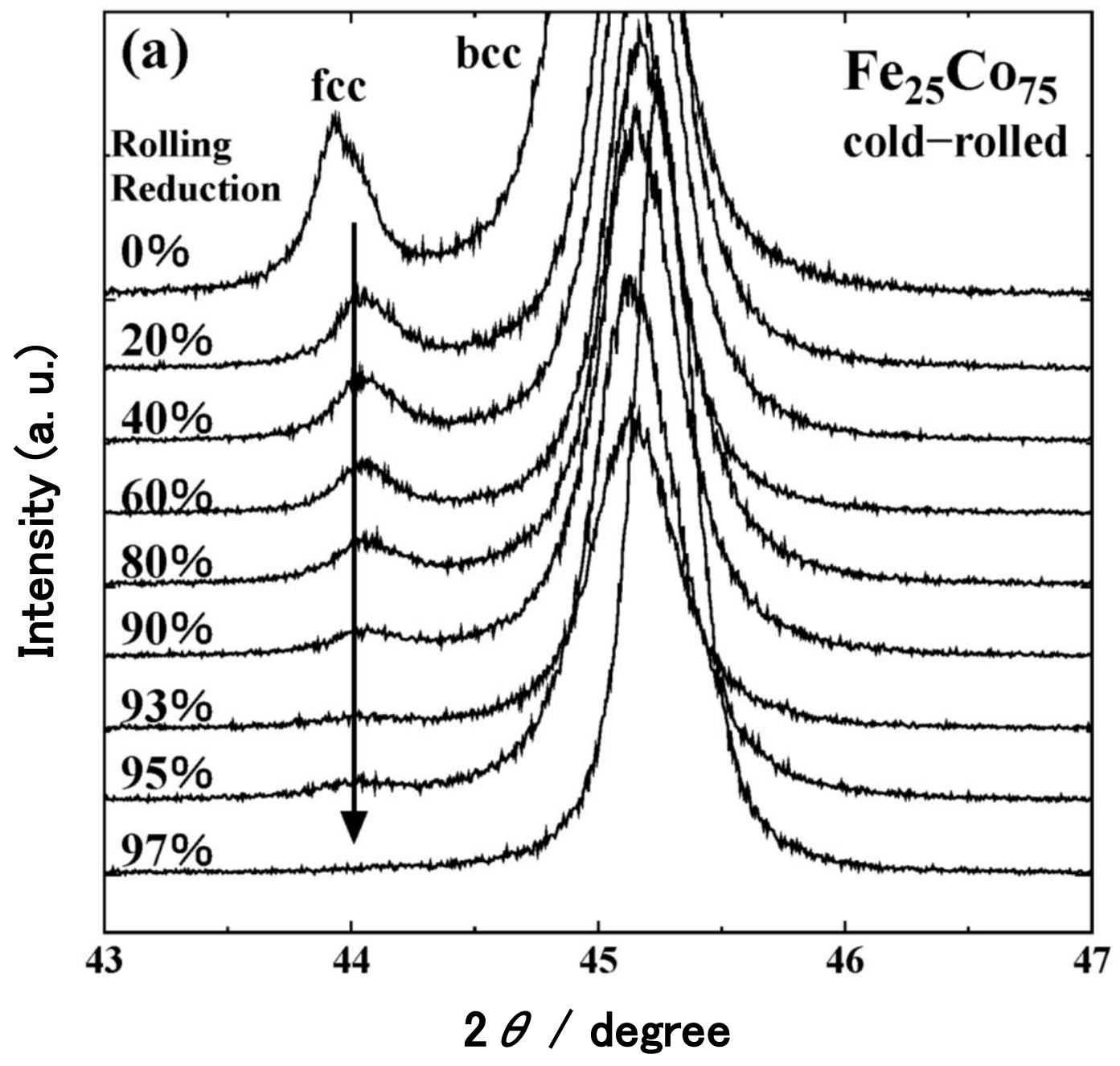

Figure 8(a) 


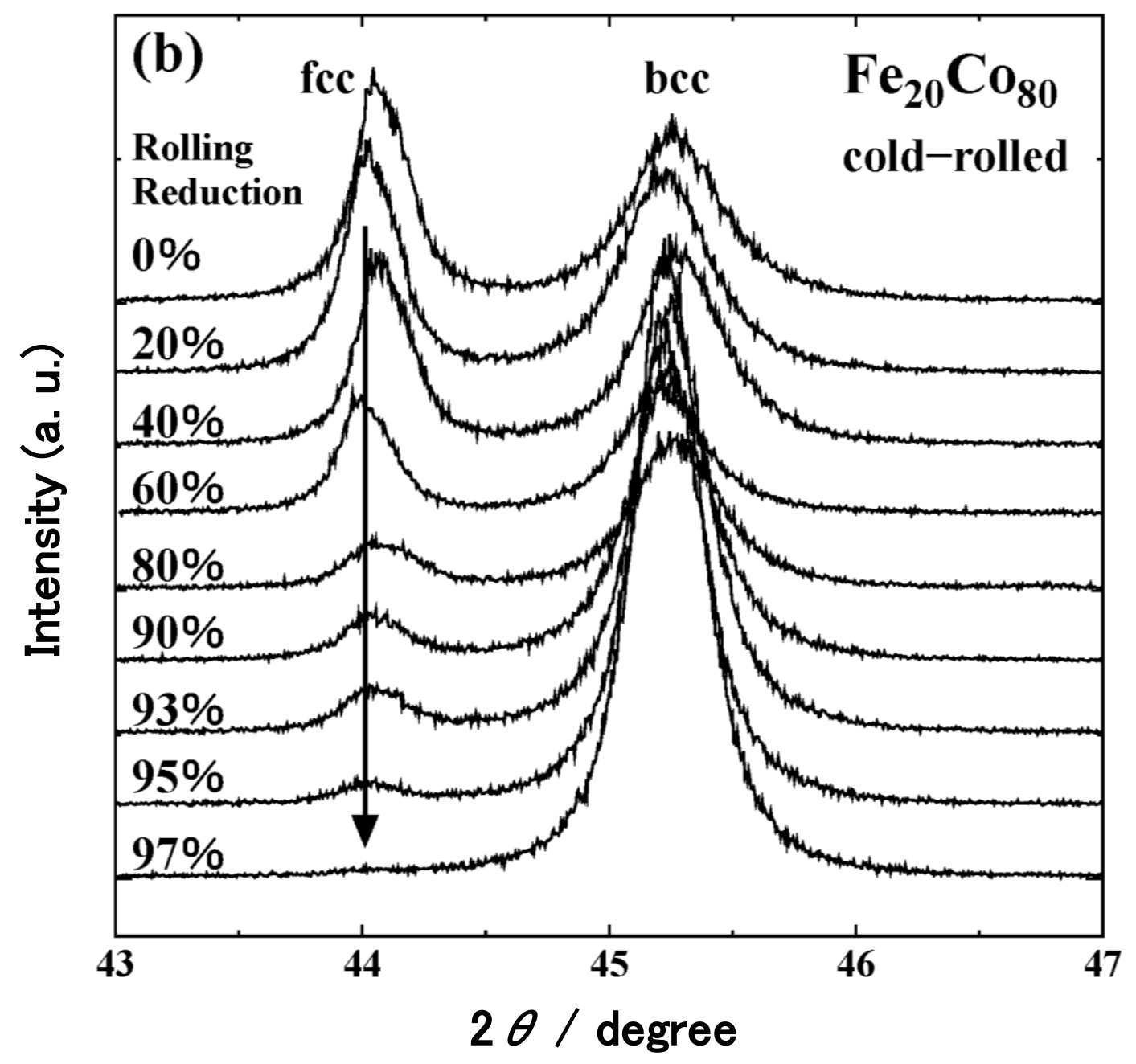

Figure $8(b)$ 


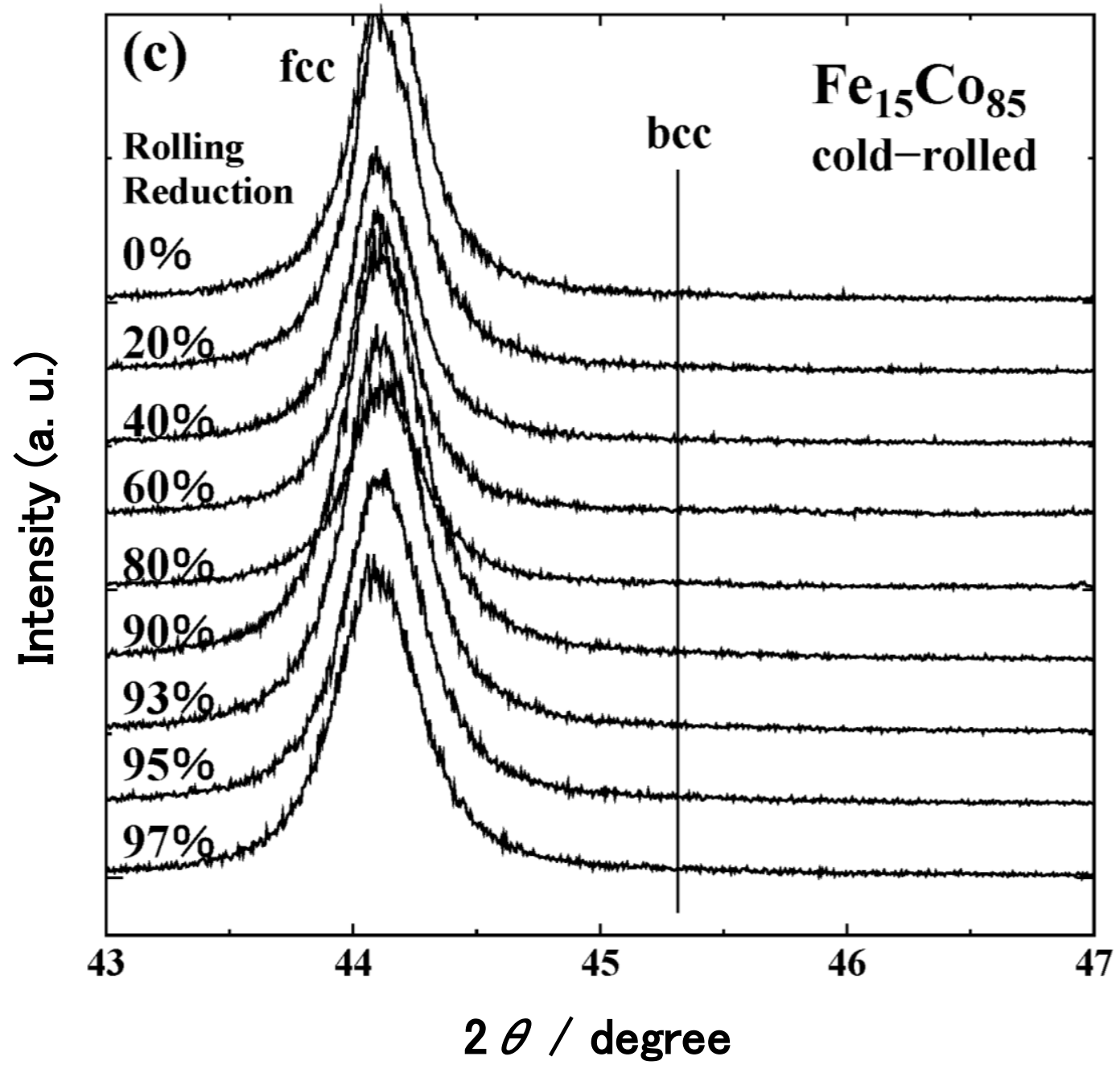

Figure 8(c) 
(a)
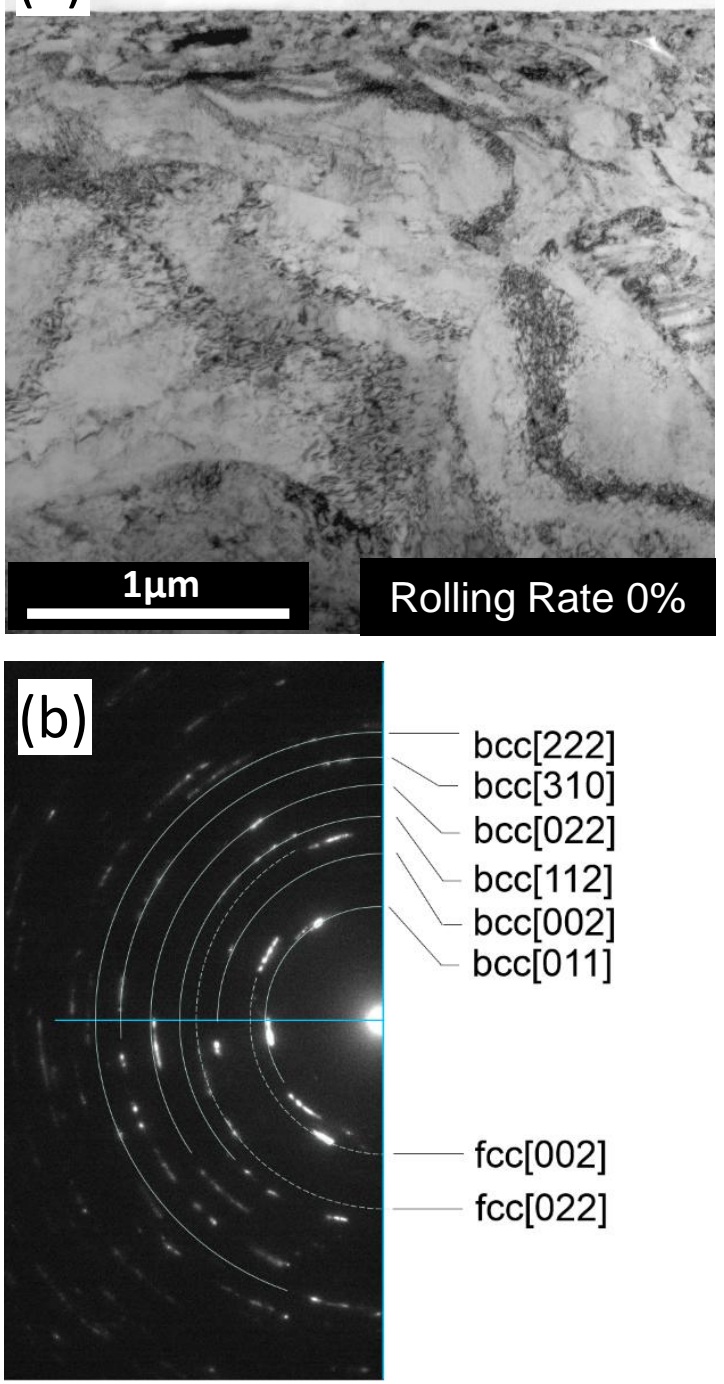

Figures 9(a),(b)
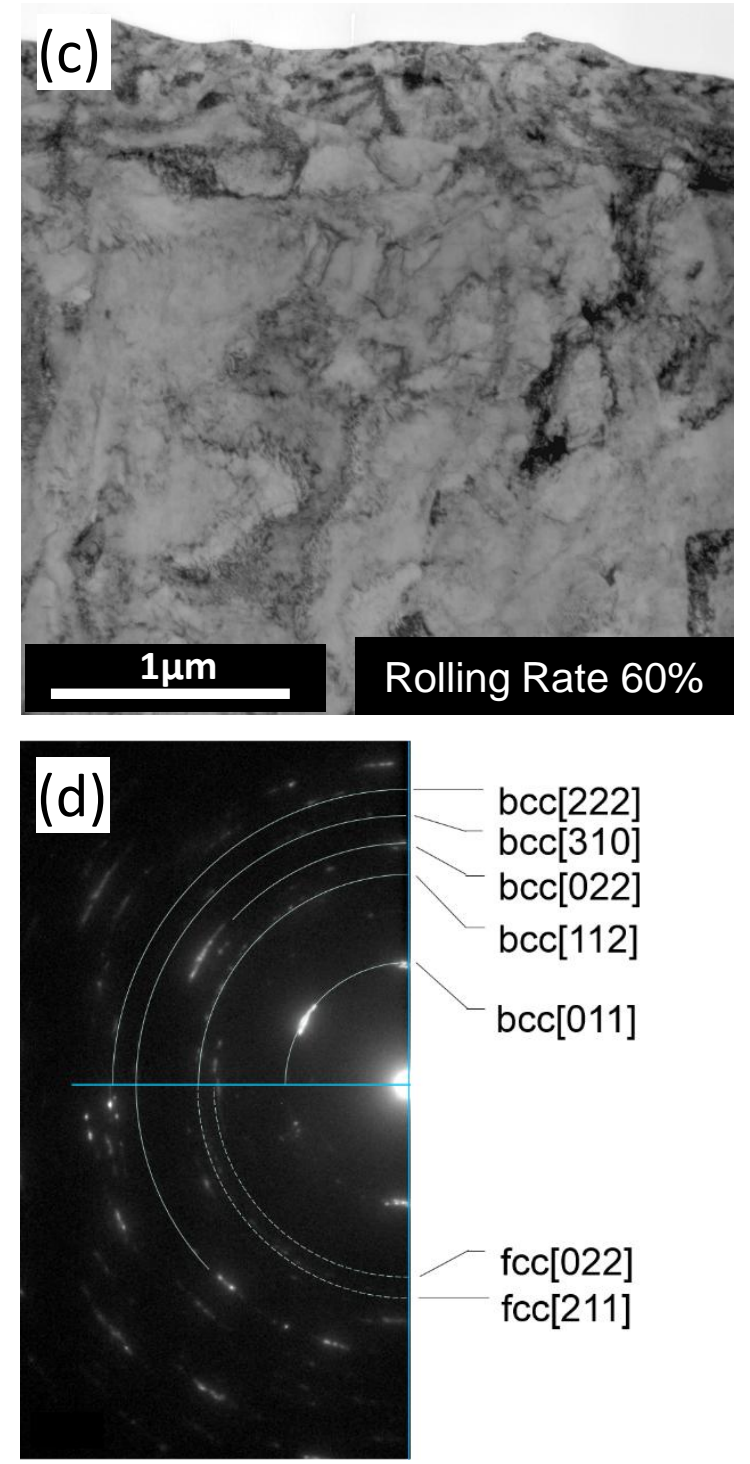

Figures 9(c),(d)
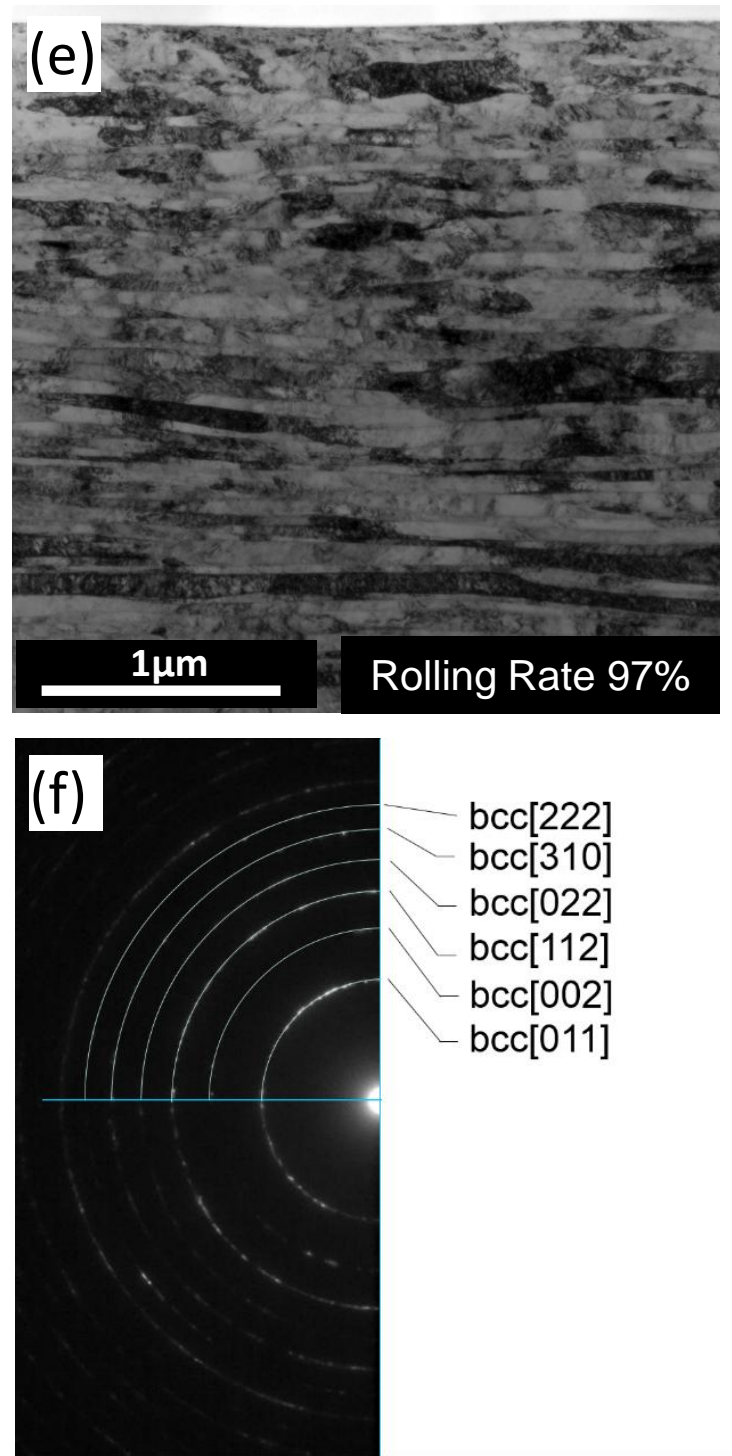

bcc[222] bcc[310] - bcc[022] bcc[112] - bcc[002] - bcc[011]

Figures 9(e),(f) 